\title{
Candida species distribution, genotyping and virulence factors of Candida albicans isolated from the oral cavity of kidney transplant recipients of two geographic regions of Brazil
}

\author{
Walicyranison Plinio da Silva-Rocha' ${ }^{1}$, Vitor Luiz de Brito Lemos ${ }^{1}$, Terezinha Inês Estivalet Svidizisnki ${ }^{3}$ \\ Eveline Pipolo Milan ${ }^{2}$ and Guilherme Maranhão Chaves ${ }^{1,4^{*}}$
}

\begin{abstract}
Background: Candida albicans is a diploid yeast that in some circumstances may cause oral or oropharyngeal infections, This investigation aimed to study the prevalence of Candida spp. and to analyze the ABC genotypes of 76 clinical isolates of $C$. albicans obtained from the oral cavity of kidney transplant patients from two distinct geographic regions of Brazil.

Methods: We typed 48 strains with ABC genotyping and Microsatelitte using primer M13 and tested three virulence factors in vitro: phospholipase activity, morphogenesis and the ability to evade from polymorphonuclear neutrophils phagocytosis.

Results: C. albicans was the most prevalent species (86.4\%), followed by C. tropicalis (4.5\%). C. albicans genotype A was the most prevalent (58 isolates; 76.4\%), followed by genotype C (15 isolates; 19.7\%) and genotype B (3 isolates; 3.9\%). When Microsatellite technique with primer M13 was applied, $80 \%$ of the isolates from the South were placed within the same cluster. The majority of Genotype $C$ strains were grouped together within two different clusters. Genotype $C$ was considered more resistant to PMNs attack than genotypes A and B. Strains isolated from the South of Brazil showed also better ability to combat PMNs phagocytosis.
\end{abstract}

Conclusions: We found a high rate of C. albicans genotype $C$ strains isolated from the oral cavity of this group of patients. This study characterized oral C. albicans strains isolated from kidney transplant recipients and will contribute to a better understanding of the pathogenesis of oral candidiasis.

Keywords: Candida spp, Oral candidiasis, Kidney transplant recipients, Genotyping, Virulence factors

\section{Background}

Despite the fact that Candida spp. belong to the normal oral microbiota, living on the tongue, gums, palate and saliva of healthy individuals as commensal yeasts, they can cause oral or oropharyngeal infections [1,2]. Candida spp. have been isolated from 40 to $60 \%$ of healthy mouths,

\footnotetext{
* Correspondence: guilherme.chaves@ufrnet.br

${ }^{1}$ Laboratório de Micologia Médica e Molecular, Departamento de Análises Clínicas e Toxicológicas, Universidade Federal do Rio Grande do Norte, Natal, Rio Grande do Norte, Brazil

${ }^{4}$ Universidade Federal do Rio Grande do Norte, Centro de Ciências da Saúde, Departamento de Análises Clínicas e Toxicológicas, Laboratório de Micologia Médica e Molecular. Rua Gal. Gustavo Cordeiro de Faria S/N. Petrópolis, Natal, Rio Grande do Norte, Brazil

Full list of author information is available at the end of the article
}

whereas oral candidiasis is more common in immunodeficient individuals, those with severe underlying diseases, and upper denture wearers $[3,4]$.

Despite the fact that other less virulent Candida species such as C. glabrata, C. tropicalis, C. parapsilosis, C. krusei and $C$. dubliniensis have also been isolated from the saliva of patients with or without oral candidiasis, C. albicans is still the most frequent species associated with oral lesions [5].

Several factors may contribute for the transition from commensal yeasts to pathogenic forms which are related to impaired host immune system associated with the virulence of the micro-organism. The main virulence factors of C. albicans include bud-to-hypha transition 
(also called morphogenesis), adhesion to human epithelial and endothelial cells, biofilm formation, the ability to secrete hydrolytic enzymes (mainly proteinases and phospholipases), phenotypic switching (white-opaque transition) as well as evasion of host immune cells [6,7].

Some studies have evaluated C. albicans ABC genotypes isolated from the oral cavity of different individuals and the results seem to be very variable, according to the population evaluated. For instance, a study with 11 diabetic patients with periodontitis revealed that $51.6 \%$ subgingival C. albicans isolates belonged to genotype B [8], while other investigation has found genotype A as predominant [9].

The prevalence of oral candidiasis in renal transplant recipients described in the literature ranges from $9.4 \%$ to $46.7 \%$ [10-12]. A study performed in Mexico by De La Rosa-Garcia et al [11], reports $18.7 \%$ of cases of oral candidiasis in a total of 90 kidney transplanted recipients.

Our group has previously published a comparison of some virulence factors (biofilm production, adhesion to human buccal epithelial cells and proteinase activity) among C. albicans and non-C. albicans Candida isolates obtained from the oral cavity of kidney transplant recipients from Natal, Rio Grande do Norte, Brazil [13]. This study is a follow up of this previous publication including other strains belonging to another geographic region of Brazil. In addition, other virulence attributes were investigated. Therefore, the objectives of the present study were to determine Candida species distribution and to genotypically characterize $48 \mathrm{C}$. albicans strains isolated from the buccal cavity of 154 kidney transplanted recipients from two different geographic regions of Brazil (Northeast and South). In addition, the strains were phenotypically characterized for the ability to express the following virulence factors in vitro: The secretion of phospholipase, the transition from yeast cells to hyphae (morphogenesis) and the ability to resist to phagocytosis by polymorphonuclear neutrophils.

\section{Methods}

\section{Strains selection}

During a 3 months-period, 154 patients from two different geographic regions of Brazil (111 from Natal, Rio Grande do Norte and 43 from Maringa, Parana) were subjected to clinical examination of the oral cavity for candidiasis diagnosis, according to the criteria established for oral lesions in HIV patients recommended by the EC-Clearinghouse and World Health Organization classifications [14]. Only patients who agreed to take part on a surveillance confidential study, in accordance to the Local Research Ethics committee from The Onofre Lopes University Hospital, approved under the number 152/07, were enrolled in this study. Strains isolates from oral colonization (without any symptoms) or during episodes of oral candidiasis were evaluated in this study. For genotyping and virulence studies, we randomly selected 48 clinical strains of C. albicans (38 from Natal, Rio Grande do Norte and 10 from Maringa, Parana). All the isolates are described in Table 1. The samples were stocked on YPD glycerol (10 g/L yeast extract, $20 \mathrm{~g} / \mathrm{L}$ peptone, $20 \mathrm{~g} / \mathrm{L}$ dextrose and $3 \%$ glycerol) at $-80^{\circ} \mathrm{C}$ at the Laboratório de Micologia Médica e Molecular, Universidade Federal do Rio Grande do Norte, Brazil. C. albicans ATCC90028 and SC5314 were included in this study as reference strains.

\section{Samples collection and yeasts identification}

Samples containing $2 \mathrm{~mL}$ of saliva were collected from all patients, by previous stimulation with chewing gums. When lesions were present, a sterile swab was rubbed on the mucosal surface of the buccal cavity. Subsequently, $100 \mu \mathrm{L}$ of cells suspensions were inoculated on the surface of Sabouraud Dextrose Agar (SDA; Oxoid, UK) added $300 \mu \mathrm{g} / \mathrm{mL}$ of cloramphenicol (Park-Davis), by using a Drigalsky loop. The plates were incubated at $37^{\circ} \mathrm{C}$ for 48 h. Yeast colonies were plated on CHROMagar Candida ${ }^{\circ}$ (CHROMagar Microbiology, Paris, France) to check for purity and screening for different color colonies. Species identification was based on the characteristics of the cells observed microscopically after cultivation on cornmeal agar added Tween 80, as well as assimilation and fermentation testing and ID32C System (bioMérieux Marcy l'Etoile, France), whenever it was necessary [15]. Strains belonging to the Candida parapsilosis species complex were identified previously with molecular methods [13].

\begin{tabular}{|c|c|c|c|}
\hline Variables & Natal $(n, \%)$ & Maringa $(n, \%)$ & Total $(n, \%)$ \\
\hline \multicolumn{4}{|l|}{ Sex } \\
\hline Male & $64(73.6)$ & $23(26.4)$ & $87(100)$ \\
\hline Female & $47(70.1)$ & $20(29.9)$ & $67(100)$ \\
\hline \multicolumn{4}{|l|}{ Age } \\
\hline 12-18 years old & $6(85.7)$ & $1(14.3)$ & $7(100)$ \\
\hline 19-34 years old & $44(81.5)$ & $10(18.5)$ & $54(100)$ \\
\hline $35-64$ years old & $59(64.8)$ & $32(35.5)$ & $91(100)$ \\
\hline 65 years old or more & $2(100)$ & $0(0)$ & $2(100)$ \\
\hline \multicolumn{4}{|l|}{ Underlying disease } \\
\hline Diabetic nephropathy & $8(66.7)$ & $4(33.3)$ & $12(100)$ \\
\hline Arterial hypertension & $47(85.4)$ & $8(14.6)$ & $55(100)$ \\
\hline Glomerulonephritis & $23(76.7)$ & $7(23.3)$ & $30(100)$ \\
\hline Polycystic kidney diseases & $6(66.7)$ & $3(33.3)$ & $9(100)$ \\
\hline Other & $27(56.25)$ & $21(43.75)$ & $48(100)$ \\
\hline
\end{tabular}




\section{C. albicans DNA extraction}

C. albicans cells were grown overnight in YPD liquid medium (Dextrose $20 \mathrm{~g} / \mathrm{L}$, peptone $20 \mathrm{~g} / \mathrm{L}$, Yeast Extract $10 \mathrm{~g} / \mathrm{L}$ ) incubated at $30^{\circ} \mathrm{C}$ rotated at $200 \mathrm{rpm}$ in a gyratory shaker (TE-420, Tecnal ${ }^{\bullet}$ Piracicaba, Brazil). DNA was extracted using the PrepMan Ultra sample preparation reagent (Applied Biosystems, Foster City, CA) according to the manufacturer's instructions. Genomic DNA concentration and purity were checked with a NanoDrop instrument (Thermo Scientific; Amersham Pharmacia Biotech, Wilmington, DE, USA).

\section{Microsatellite typing PCR and $A B C$ genotyping}

Microsatellite typing was performed using the primer M13 (5' GAGGGTGGCGGTTCT-3') (IDT) as previously described [16]. ABC genotyping was performed with the following primers: CAINT- L (5'-ATAAGGGAAGTCGGCAAAATAGATCCGTAA-3') and CA-INT-R (5' -CCTTG GCTGTGGTTTCGCTAGATAGTAGAT-3') [17]. Briefly, $1.0 \mu \mathrm{L}$ of DNA $40 \mathrm{ng} / \mu \mathrm{L}$ was added to 29 PCR Master Mix (Promega) to a final volume of $25 \mu \mathrm{L}$. The samples were amplified in a Thermocycler (Amplitherm TX96, USA) using the following cycling parameters: one initial cycle of $94^{\circ} \mathrm{C}$ for $3 \mathrm{~min}$ followed by 30 cycles of $1 \mathrm{~min}$ at $94^{\circ} \mathrm{C}$, $1 \mathrm{~min}$ at $57^{\circ} \mathrm{C}, 1 \mathrm{~min}$ at $72^{\circ} \mathrm{C}$ and a final cycle of $5 \mathrm{~min}$ at $72^{\circ} \mathrm{C}$. For Microsatellite typing, $1.0 \mu \mathrm{L}$ of DNA $40 \mathrm{ng} / \mu \mathrm{L}, 2.5 \mu \mathrm{L}$ of $10 \times$ PCR buffer $(100 \mathrm{mM}$ Tris- $\mathrm{HCl}$, $\mathrm{pH}$ 8.3, $500 \mathrm{mM} \mathrm{KCl}, 3.5 \mathrm{mM} \mathrm{MgCl}$ ), $5 \mu \mathrm{L}$ of dNTPmix (100 mM each dNTP), $1.0 \mu \mathrm{L}$ of each primer $(50 \mathrm{pmol} /$ $\mu \mathrm{L}), 0.13 \mu \mathrm{L}$ of tween 20 and 1.0 unit of Taq DNA polymerase were added to a final volume of $25 \mu \mathrm{L}$. Forty-five cycles of amplification were performed using the same cycling parameters described previously, except that the annealing temperature was $36^{\circ} \mathrm{C}$ for the Microsatellite typing. PCR products were size-separated by agarose gel electrophoresis, and the gel was stained in a $0.5 \mu \mathrm{g} /$ $\mathrm{mL}$ ethidium bromide buffer solution (TAE).

\section{Computer-assisted Microsatellite data analysis}

Gel images were analyzed with the GelCompar II software, version 4.5 and BioNumerics (Applied Maths, Kortrijk, Belgium). The similarities between the profiles were calculated using the Dice coefficient to generate the matrixes of similarity coefficients to dendrogram constructions. For profile clustering, the unweighted pair-group method with arithmetic averages was used with a tolerance of $2 \%$.

\section{Tests for hyphae formation}

An initial amount of $10^{6}$ cells $/ \mathrm{mL}$ in YPD $+20 \%$ FBS (Fetal Bovine Serum, Sigma-Aldrich ${ }^{\circ}$, Brazil) was incubated at $37^{\circ} \mathrm{C}$, with gyratory shaking at $200 \mathrm{rpm}$. After $3 \mathrm{~h}$ incubation, samples of the cultures were mixed with an equal volume of $10 \%$ formaldehyde to arrest further development and the mean morphology index (MI) was determined [18]. Values close to 1 indicate a population of spheroidal yeast cells and values close to 4 indicate a population of true hyphal cells, with values between 1 and 4 indicating mixed or pseudohyphal morphologies.

\section{Phospholipase assay}

Phospholipase activity was estimated by the egg yolk agar method [19], with inocula prepared from overnight NGY (Neopeptone (Difco, Detroit, MI) $1 \mathrm{~g} / \mathrm{L}$, glucose $4 \mathrm{~g} / \mathrm{L}$ and yeast extract $1 \mathrm{~g} / \mathrm{L}$ ) cultures standardized to $2 \times 10^{5}$ cells $/ \mathrm{mL}$.

Candida albicans killing by polymorphonuclear neutrophils PMN freshly isolated from blood samples of a single healthy volunteer on the day of the experiment [20] were suspended in Eagle's minimal essential medium (Gibco) + $20 \mathrm{mM}$ HEPES, $\mathrm{pH} 7.2$, and standardized to $8 \times 10^{5}$ $\mathrm{PMN} / \mathrm{mL}$. C. albicans cells grown overnight in NGY washed and resuspended at $5 \times 10^{6}$ yeasts $/ \mathrm{mL}$ in HEPESbuffered Eagle's minimal essential medium containing one-tenth volume of fresh human plasma. Equal volumes of PMN and yeast suspensions were mixed and incubated at $37^{\circ} \mathrm{C}$ for $3 \mathrm{~h}$ with rotation at $50 \mathrm{rpm}$. The phagocytosis of $C$. albicans were established by counting in triplicate the number of yeasts inside or attached in 100 PMNs [21].

\section{Statistical analysis}

Data were analyzed using the statistical software "GraphPad", version 3.0. Results were presented as mean \pm standard deviation, and differences were analyzed by the Mann-Whitney test. For all the analyses, P was considered a default value of 0.05 and the confidence interval of $95 \%$.

\section{Results}

\section{Patients demographic data}

Patient's clinical and demographic data are summarized in Table 1. For both regions, the majority of the patients had arterial hypertension as the most frequent underlying disease. In addition, the most frequent age class was 35 to 64 years old (Table 1 ).

\section{Microbiology profiling of Candida spp. in oral candidiasis} From the strains obtained from Natal, RN (Northeast), it was possible to isolate yeasts from 70 out of 111 patients (63.1\%), while from Maringa, 12 out of 43 (27.5\%) Candida spp positive cultures were obtained. Species distribution for both regions is described in Table 2. C. albicans was the most predominant species found in both cities, followed by $C$. tropicalis. In only a single patient from Maringa it was possible to isolate three strains belonging to different Candida species (C. albicans, C. glabrata, C. tropicalis). 
Of note, only one sample from each patient was collected, except for three different patients from the South region of Brazil. From patient 37, strain $06 \mathrm{~S}$ was obtained from saliva, while strain $06 \mathrm{~L}$ from oral lesion. Patient 38 had two C. albicans strains collected from the same lesion, showing two clear different phenotypes (10S, smooth and $10 \mathrm{R}$, with rough colonies). Patient 40 showed two different lesions and two strains were obtained, one from the tongue and another one from the gums (15 T and 15G, respectively) in addition to a strain obtained from saliva (15S).

\section{ABC typing of Candida albicans}

DNA from all the 76 strains of C. albicans and the reference strains ATCC90028 and SC5314 was submitted to $\mathrm{ABC}$ typing. Genotype A was the most prevalent with 58 isolates (76.4\%) followed by Genotype C, with 15 strains (19.27\%) and Genotype B, with 3 isolates (3.9\%; Table 3). The same trend was observed when the strains obtained from each region were analyzed separately: In the Northeast of Brazil, C. albicans genotype A was the most prevalent, with 42 isolates $(71.2 \%)$, followed by Genotype C $(\mathrm{n}=14$ isolates; $23.7 \%)$ and Genotype B, with 3 strains (5.1\%). The higher incidence of genotype A was also found in the South of the country with 16 isolates (94.1\%) followed by genotype C ( $\mathrm{n}=1$ isolate; $5.9 \%)$. C. albicans genotype B was not observed for the isolates obtained from this region (Table 3).

\section{Candida albicans microsatellite typing versus ABC genotyping}

We randomly selected 48 isolates of C. albicans including some strains belonging to genotype A (21 from Natal and 10 from Maringa) an all the other strains belonging to genotypes $\mathrm{B}$ and $\mathrm{C}$ from both regions and performed Microsatellite genotyping. The genomic DNA of all of the 48 isolates was successfully amplified with the M13 primer, which targets genome repetitive sequences. The DNA amplification generated well-defined band patterns, ranging from $100 \mathrm{pb}$ to $2 \mathrm{~kb}$. The microsatellite technique showed sufficient discriminatory power for recognizing intraspecific variation (Figure 1). As expected, the external

Table 2 Species distribution of Candida spp. isolated of oral cavity of kidney transplant recipients from two different geographic regions of Brazil: Natal, RN and Maringa, PR

\begin{tabular}{cccc}
\hline Species & Natal $(\mathbf{n}, \%)$ & Maringá $(\mathbf{n}, \%)$ & Total $(\mathbf{n}, \%)$ \\
\hline Candida albicans & $59(77.6)$ & $17(22.4)$ & $76(100)$ \\
Candida dubliniensis & $2(100)$ & $0(0)$ & $2(100)$ \\
Candida glabrata & $2(66.7)$ & $1(33.3)$ & $3(100)$ \\
Candida tropicalis & $3(75)$ & $1(25)$ & $4(100)$ \\
Candida orthopsilosis & $2(100)$ & $0(0)$ & $2(100)$ \\
Candida metapsilosis & $2(100)$ & $0(0)$ & $2(100)$ \\
$\quad$ Total & $69(78.4)$ & $19(21.6)$ & $88(100)$ \\
\hline
\end{tabular}

control strains of C. albicans, SC5314 and ATCC90028, were placed in completely different clusters by the dendrogram analysis performed using GelCompar II, proving the efficiency of the technique in separating strains isolated from different geographic areas. These control strains showed $75 \%$ similarity and were placed together within a different cluster of all the other clinical isolates (Figure 1).

We could not detect any particular cluster of either colonizing or infecting strains. In addition, in both cases, strains with $100 \%$ similarity obtained from different patients were found. Regarding to the comparisons of genetic relatedness within the two different geographic regions of Brazil, we could observe an enriched cluster for Maringa (South), where $80 \%$ of the strains were placed together. In addition, they ranged from $80 \%$ up to $93 \%$ similarity among them.

Other interesting finding is associated with some degree of correlation observed between the $A B C$ type of $C$. albicans and the high percentage of similarity among these isolates when Microsatellite primer M13 was used. In most of the cases, strains with identical percentage of similarity determined with primer M13, also had the same A or C genotype (except for strains 02 and 85 from Natal as well as $15 \mathrm{~T}$ and 18A from Maringa; $\mathrm{A}$ and $\mathrm{C}$ genotypes in both cases). In addition, C. albicans genotype $C$ strains from Natal were placed within two well-defined separated clusters with proven high relatedness (more than $90 \%$ similarity within the same cluster). In relation to genotype B, two out of three isolates showed a similarity of $94 \%$, being placed in the same cluster (Figure 1).

Furthermore, when different strains were obtained from different samples of the same patient, they all had the same ABC genotype (genotype A). Nevertheless, Microsatellite using primer M13 showed higher discriminatory power, because these strains were not considered identical with the latest technique, showing some degree of genetic variability, when this method was used.

\section{Virulence attributes of Candida albicans A, B and C genotypes}

For all the virulence factors tested, we only performed statistical analysis for comparisons among strains belonging to genotypes $\mathrm{A}$ and $\mathrm{C}$, because of the low number of isolates belonging to genotype $\mathrm{B}$ found. In relation to phospholipase production, all the strains were able to produce the enzyme, regardless if they were obtained from episodes of colonization or infection. For genotype A, a Mean $\mathrm{Pz}$ of $0.51 \pm 0.04$ was obtained, while for genotype $C$, a Mean of $0.55 \pm 0.05$, while for the genotype B, the Mean Pz was $0.57 \pm 0.07$. No statistical differences were found when strains belonging to genotypes A and C were compared (Table 3). 
Table 3 Patients enrolled in this study, geographic region ABC genotyping and virulence attributes of Candida albicans

\begin{tabular}{|c|c|c|c|c|c|c|}
\hline Isolate number & Clinical condition & Procedence & $A B C$ typing & $\begin{array}{c}\text { Phospholipase activity } \\
\text { PZ (cm) }\end{array}$ & $\begin{array}{l}\text { Morphology } \\
\text { Index (MI) }\end{array}$ & $\begin{array}{c}\text { No of } C \text {. albicans cells phagocytosed } \\
\left.\text { by } 100 \text { PMNs* }^{*} \%\right)\end{array}$ \\
\hline 1 & Colonization & Natal & B & $0.6 \pm 0.07$ & $2.46 \pm 0.70$ & $134 \pm 15.3$ \\
\hline 2 & Colonization & Natal & A & $0.55 \pm 0.04$ & $3.43 \pm 0.77$ & $115 \pm 14.6$ \\
\hline 3 & Colonization & Natal & A & $0.48 \pm 0.06$ & $3.22 \pm 0.64$ & $66 \pm 7.9$ \\
\hline 5 & Infection & Natal & C & $0.58 \pm 0.02$ & $2.23 \pm 0.57$ & $98 \pm 6.7$ \\
\hline 6 & Colonization & Natal & A & $0.53 \pm 0.01$ & $2.24 \pm 0.51$ & $100 \pm 12.5$ \\
\hline 8 & Colonization & Natal & A & $0.57 \pm 0.04$ & $1.86 \pm 0.43$ & $130 \pm 19$ \\
\hline 10 & Infection & Natal & B & $0.56 \pm 0.12$ & $2.17 \pm 0.62$ & $166 \pm 8.4$ \\
\hline 11 & Colonization & Natal & C & $0.58 \pm 0.08$ & $2.15 \pm 0.77$ & $28 \pm 3.5$ \\
\hline 12 & Infection & Natal & A & $0.54 \pm 0.02$ & $2.46 \pm 0.56$ & $150 \pm 11.1$ \\
\hline 13 & Colonization & Natal & C & $0.6 \pm 0.03$ & $2.17 \pm 0.65$ & $126 \pm 31.6$ \\
\hline 17 & Colonization & Natal & A & $0.52 \pm 0.03$ & $3.63 \pm 0.63$ & $98 \pm 20.2$ \\
\hline 20 & Colonization & Natal & A & $0.44 \pm 0.01$ & $2.85 \pm 0.81$ & $86 \pm 21.2$ \\
\hline 21 & Colonization & Natal & A & $0.4 \pm 0.06$ & $2.78 \pm 0.92$ & $114 \pm 21.5$ \\
\hline 23 & Colonization & Natal & $C$ & $0.53 \pm 0.09$ & $2.45 \pm 0.67$ & $101 \pm 11.4$ \\
\hline 24 & Infection & Natal & A & $0.51 \pm 0.10$ & $3.05 \pm 0.74$ & $132 \pm 13.9$ \\
\hline 28 & Infection & Natal & A & $0.55 \pm 0.04$ & $2.84 \pm 0.80$ & $165 \pm 9.5$ \\
\hline 30 & Colonization & Natal & C & $0.52 \pm 0.04$ & $2.17 \pm 0.62$ & $119 \pm 20$ \\
\hline 31 & Colonization & Natal & A & $0.49 \pm 0.03$ & $2.64 \pm 0.82$ & $129 \pm 15$ \\
\hline 32 & Colonization & Natal & A & $0.49 \pm 0.12$ & $2.81 \pm 0.65$ & $123 \pm 13.2$ \\
\hline 34 & Colonization & Natal & A & $0.52 \pm 0.07$ & $2.36 \pm 0.64$ & $156 \pm 16.5$ \\
\hline 37 & Colonization & Natal & B & $0.57 \pm 0.01$ & $3.38 \pm 0.80$ & $124 \pm 19.1$ \\
\hline 40 & Infection & Natal & A & $0.51 \pm 0.06$ & $3.7 \pm 0.56$ & $142 \pm 15.9$ \\
\hline 41 & Colonization & Natal & A & $0.54 \pm 0.03$ & $2.7 \pm 0.69$ & $172 \pm 21.1$ \\
\hline 44 & Infection & Natal & A & $0.48 \pm 0.03$ & $2.8 \pm 0.77$ & $176 \pm 11.6$ \\
\hline 46 & Colonization & Natal & A & $0.46 \pm 0.04$ & $2.81 \pm 0.77$ & $172 \pm 20.1$ \\
\hline 50 & Colonization & Natal & A & $0.54 \pm 0.04$ & $3.24 \pm 0.88$ & $157 \pm 36.6$ \\
\hline 51 & Colonization & Natal & A & $0.51 \pm 0.02$ & $2 \pm 0.43$ & $130 \pm 19.5$ \\
\hline 53 & Colonization & Natal & $C$ & $0.53 \pm 0.09$ & $2.79 \pm 0.71$ & $132 \pm 15.9$ \\
\hline 54 & Colonization & Natal & A & $0.47 \pm 0.02$ & $1.8 \pm 0.40$ & $132 \pm 9.2$ \\
\hline 60 & Colonization & Natal & C & $0.57 \pm 0.03$ & $2.15 \pm 0.36$ & $146 \pm 9$ \\
\hline 61 & Colonization & Natal & A & $0.49 \pm 0.01$ & $2.48 \pm 0.75$ & $142 \pm 9.2$ \\
\hline 70 & Colonization & Natal & C & $0.51 \pm 0.03$ & $2.99 \pm 0.50$ & $140 \pm 12.7$ \\
\hline 72 & Colonization & Natal & C & $0.46 \pm 0.04$ & $2.31 \pm 0.61$ & $136 \pm 9$ \\
\hline 82 & Colonization & Natal & C & $0.55 \pm 0.03$ & $3.36 \pm 0.93$ & $130 \pm 13.2$ \\
\hline 85 & Colonization & Natal & C & $0.56 \pm 0.04$ & $3.15 \pm 0.83$ & $144 \pm 9.5$ \\
\hline 107 & Colonization & Natal & C & $0.57 \pm 0.01$ & $2.39 \pm 0.63$ & $156 \pm 10.1$ \\
\hline 06A & Colonization & Maringá & A & $0.5 \pm 0.02$ & $2.34 \pm 0.71$ & $80 \pm 17.4$ \\
\hline $06 \mathrm{~L}$ & Infection & Maringá & A & $0.56 \pm 0.07$ & $2.94 \pm 0.58$ & $75 \pm 8.7$ \\
\hline 10Li & Colonization & Maringá & A & $0.55 \pm 0.01$ & $2.42 \pm 0.70$ & $176 \pm 6.1$ \\
\hline $10 \mathrm{~S}$ & Colonization & Maringá & A & $0.64 \pm 0.01$ & $2.54 \pm 0.76$ & $105 \pm 14.7$ \\
\hline $12 \mathrm{~A}$ & Colonization & Maringá & A & $0.49 \pm 0.02$ & $3.3 \pm 0.79$ & $59 \pm 16.8$ \\
\hline $12 \mathrm{~L}$ & Infection & Maringá & A & $0.51 \pm 0.05$ & $3.2 \pm 0.68$ & $90 \pm 13.2$ \\
\hline $15 \mathrm{~A}$ & Colonization & Maringá & A & $0.42 \pm 0.02$ & $2.96 \pm 0.83$ & $116 \pm 27.1$ \\
\hline
\end{tabular}


Table 3 Patients enrolled in this study, geographic region ABC genotyping and virulence attributes of Candida albicans (Continued)

\begin{tabular}{|c|c|c|c|c|c|c|}
\hline $15 G$ & Infection & Maringá & A & $0.42 \pm 0.03$ & $3.13 \pm 0.81$ & $86 \pm 21.9$ \\
\hline $15 \mathrm{~L}$ & Infection & Maringá & A & $0.47 \pm 0.08$ & $2.58 \pm 0.68$ & $76 \pm 16.5$ \\
\hline $18 \mathrm{~A}$ & Colonization & Maringá & $C$ & $0.56 \pm 0.11$ & $3.05 \pm 0.67$ & $102 \pm 11.2$ \\
\hline $111 \mathrm{~L}$ & Colonization & Natal & C & $0.55 \pm 0.03$ & $2.6 \pm 0.70$ & $80 \pm 17.4$ \\
\hline $111 R$ & Colonization & Natal & C & $0.6 \pm 0.15$ & $4 \pm 0.00$ & $11 \pm 3.2$ \\
\hline ATCC90028 & & Reference & A & $0.7 \pm 0.08$ & $3.82 \pm 0.5$ & $158 \pm 17.5$ \\
\hline SC5314 & & Reference & A & $0.52 \pm 0.04$ & $3.28 \pm 0.81$ & $137 \pm 20.6$ \\
\hline
\end{tabular}

The isolates were obtained from the oral cavity of kidney transplant recipients from Natal, RN and Maringa, PR, Brazil.

When the morphology index (MI) was used to score cells morphology, no clear differences could be observed for the three different A, B or C genotypes. The ability of the strains to change the morphology from bud cells to hyphae when grown in the presence of YPD $+20 \%$ FBS was verified for strains belonging to the three referred genotypes. Cells were predominantly found as pseudohyphae, with a mean MI ranging from $2.66 \pm 0.61$ (genotype C) to $2.77 \pm 0.69$ (genotype A). The mean MI isolates of genotype B was $2.67 \pm 0.71$. No statistical differences were observed among the isolates (Table 3).

We also investigated the ability of the different strains to resist to phagocytosis by PMNs. Therefore, the number of C. albicans cells phagocytosed by 100 PMNs was determined after three hours of co-incubation of both cells. C. albicans genotype $C$ was more resistant to PMNs attack. Strains belonging to genotype $B$ had an average of $141.33 \pm 14.27$ cells phagocytosed by 100 PMNs. Strains belonging to genotype $\mathrm{C}$ were significantly more resistant to the attack of phagocytic cells than the isolates belonging to genotype A (Mean of $109.93 \pm 12.29$ versus $121.67 \pm 16.06$, respectively; Table 3 ).

Virulence attributes of Candida albicans strains obtained from two different geographic regions of Brazil (Northeast and South).

When the pathogenicity factors were compared among all the strains obtained from the two geographic regions, the strains obtained from Maringa (South) expressed more efficiently all the virulence factors evaluated in vitro. This difference was considered statistically significant for resistance to phagocytosis by PMN (Table 4). Interestingly, 40\% of the isolates obtained from Maringa were obtained from lesions, whereas only $18.4 \%$ of the isolates from Natal were infecting (Tables 3 and 4).

\section{Discussion}

In our study including 154 patients with oral candidiasis, the vast majority of isolates were $C$. albicans. This is in accordance with other studies that although report an increase of Non-Candida albicans Candida species, $C$. albicans is still predominant [13,22-24].
Because C. albicans is the most virulent and frequently isolated species of the genus Candida from oral candidiasis, we phenotypically characterized three attributes of virulence (extracellular activity of phospholipase, morphogenesis and resistance to phagocytosis by PMNs) of 48 clinical isolates of this species obtained from the oral cavity of 154 kidney transplanted patients from two different regions of Brazil (Northeast and South). In addition, we investigated genetic relatedness of these strains with two different methodologies of genotyping ( $A B C$ typing and Microsatelitte technique with M13 primer).

We found in the present study a high incidence of $C$. albicans isolates belonging to genotype $C$ from the oral cavity of kidney transplant recipients. Nevertheless, C. albicans genotype A was still the most prevalent. The majority of other series upon oral candidiasis or oral colonization investigating $C$. albicans $A B C$ genotypes with the same method have found genotype $A$ as the most prevalent type $[9,24,25]$. C. albicans Genotype A is also predominant in other series with strains obtained from different body sites, including cases of systemic infection [17,26-29].

Interestingly, we found a high incidence of strains belonging to genotype $\mathrm{C}$ in our study. This seems to be an unusual finding. For instance, in the study of Sardi et al [8], genotype $\mathrm{C}$ was not found. The same findings were observed by Jacobsen et al. [30]. In a total of 32 individuals with $C$. albicans oral colonization, oral candidiasis and other superficial infections, only one strain belonging to genotype $\mathrm{C}$ was found. Actually, Odds et al. [28] described genotype $C$ as a rare genotype, found in only 173 isolates of 1931 C. albicans obtained from different sources of the world. To the best of our knowledge, this is the largest population study on C. albicans typing.

Another intriguing finding is that, except for two cases, all the type $C$ strains were placed together within two well-defined separated clusters in the dendrogram. Mccullough et al [17] hypothesized that C. albicans genotype $\mathrm{C}$ is probably genotype A that probably acquired an intron. This may partially explain why they were considered identical by Microsatellite technique in two occasions. Taking together, these data suggest the peculiarity of the distribution of genotypes of C. albicans isolates 


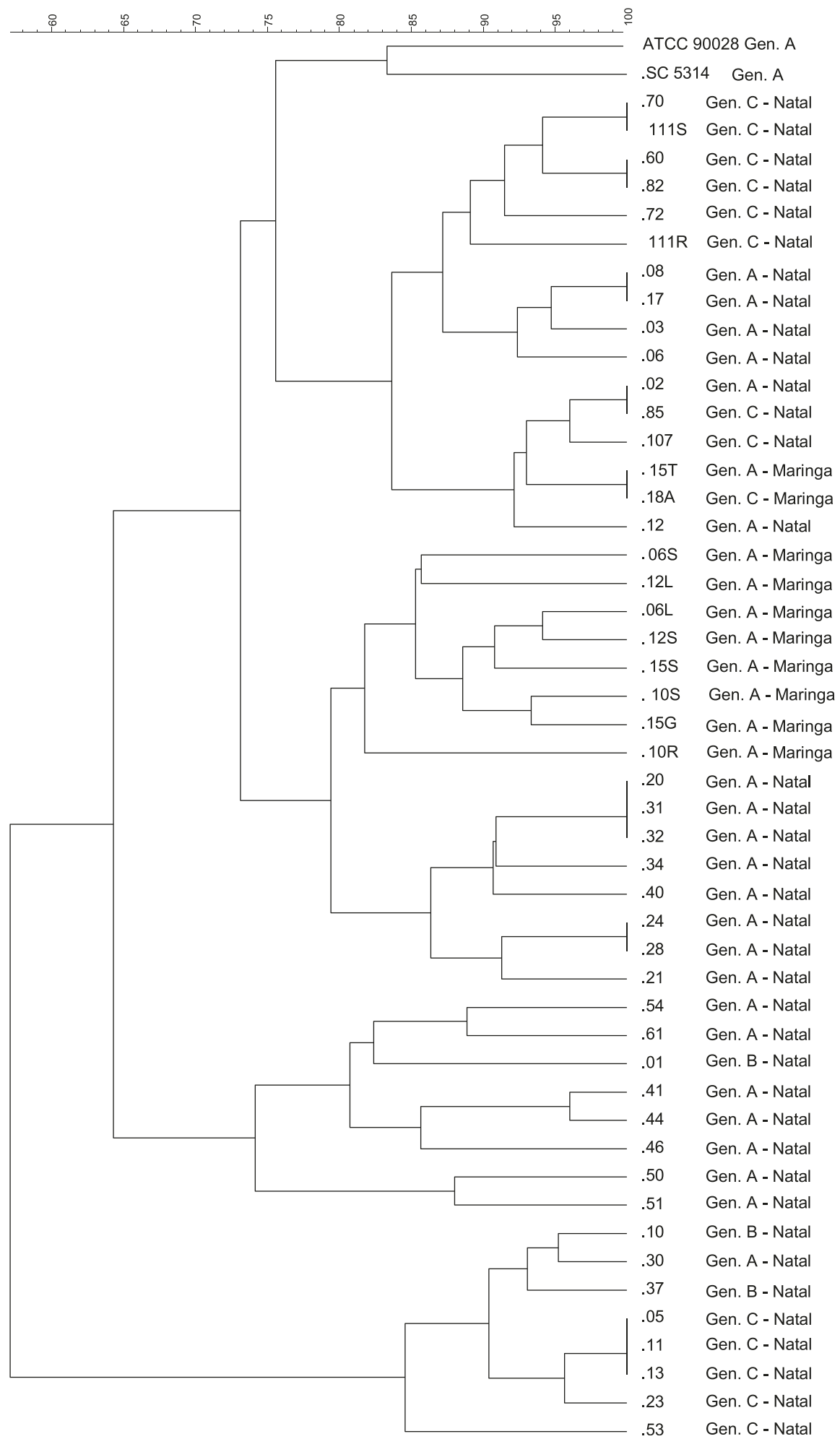

Figure 1 Unweighted pair-group method with arithmetic averages dendrogram with $2 \%$ of tolerance of 50 strains of Candida albicans clinical isolates. 
Table 4 Virulence attributes of Candida albicans isolates obtained from the oral cavity of kidney transplant recipients of two geographic regions of Brazil: Natal, RN and Maringa, PR

\begin{tabular}{cc}
\hline & Natal vs Maringa \\
\hline Phospholipase activity PZ (cm) & $0.53 \pm 0.05$ vs $0.51 \pm 0.04$ \\
Morphology index MI & $2.70 \pm 0.65$ vs $2.85 \pm 0.72$ \\
$\begin{array}{c}\text { No of C. albicans cells phagocytosed } \\
\text { by 100 PMNs** }\end{array}$ & $125.61 \pm 14.61$ vs $96.50 \pm 16.36^{*}$ \\
\hline
\end{tabular}

*Statistically significant; $\mathrm{P}<0.05$. **PMNs- = polymorphonuclear neutrophils

from the oral cavity of kidney transplant patients, firstly analyzed in our study.

Microsatellite genotyping using primer M13 showed satisfactory discriminatory power and may be applied for epidemiological studies of $C$. albicans infection with low cost and good effectiveness. This technique has not been widely used for this species [21], but has been largely used to type Cryptococcus neoformans [16,31].

The fact that we have found some strains obtained from different patients considered undistinguishable $(100 \%$ similarity) is not unusual. Other authors have described that it is possible that unrelated strains share the same genotype. For instance, Sampaio et al [32] using Microsatellite technique with CAI4 locus found that in 73 independent vaginal isolates, 44 genotypes could be detected. In addition, we could not completely rule out the possibility of strain cross-contamination while their staying in Hospital.

One of our remarkable findings was the placement of most of the strains from the South of Brazil within the same cluster. They also shared the same ABC type (genotype A). This fact may be partially explained due to $C$. albicans co-evolution with humans in determined geographic regions once this species belongs to the normal oral microbiota [28].

We found some degree of correspondence of strains genetic relatedness when both genotyping methodologies were applied. Only in two occasions, strains with different A or C types were designated as identical with Microsatellite technique. This difference reinforces the necessity of a combination of at least two different techniques for $C$. albicans strains typing [33].

Besides the fact we have found a high rate of type $C$ strains of $C$. albicans, these strains were also statistically more resistant to phagocytosis by PMNs than genotypes $\mathrm{A}$ and B strains. Although at the moment of strains collection only one genotype $\mathrm{C}$ strain was obtained from patients with lesions, the fact that they were immunosuppressed individuals and colonized by possibly virulent strains that were able to highly express the virulence factors evaluated in vitro may influence future clinical outcomes.

Related to the virulence factors expressed by the isolates from Natal and Maringa, it was possible to observe that the isolates from the South of Brazil were markedly resistant to phagocytosis by PMNs. A recent study regarding the characterization of oral biofilms formed on mucosal surfaces found that a strong migration of PMNs which formed intense nests of aggregates juxtaposed to mucosal biofilms. In addition, in sites with thicker biofilms, neutrophils migrated through the entire width of the mucosa, reinforcing the importance of specific white cells also in oral candidiasis [34].

\section{Conclusions}

A limitation of our study was the low number of isolates, specifically belonging to genotype B. Nevertheless we could demonstrate the peculiarities of $C$. albicans strains obtained from the oral cavity of kidney transplant recipients of two different regions of Brazil. Considering that this country has continental dimensions, we found that most of the strains of each different region were placed in the same cluster and were markedly resistant to phagocytosis by PMNs. In addition, we also found a high rate of genotype $\mathrm{C}$ (a rare genotype) strains isolated from the oral cavity of this group of patients. To the best of our knowledge, this study is the first one to characterize oral C. albicans strains of kidney transplant recipients from two different regions of a continental size country (Brazil).

\begin{abstract}
Abbreviations
C: Candida; spp: Species; PMN: Polymorphonuclear; YPD: Yeast peptone dextrose; g/L: Grams per liter; ${ }^{\circ} \mathrm{C}$ : Celsius degrees; ATCC: American Type Culture Collection; SDA: Sabouraud dextrose agar; UK: United Kingdom; $\mu \mathrm{g} / \mathrm{mL}$ : Micrograms per milliliter; h: Hour; DNA: Deoxyribonucleic acid; rpm: Revolutions per minute; CA: California; DE: Delaware; USA: United States of America; PCR: Polymerase chain reaction; G: Guanine; A: Adenine; C: Cytosine; T: Thymine; IDT: Integrated DNA technologies; $\mu$ L: Microliter; $\mathrm{ng} / \mu \mathrm{L}$ : Nanograms per microliter; $\mathrm{mM}$ : Millimolar; $\mathrm{HCl}$ : Chloridric acid; $\mathrm{pH}$ : Potencial hydrogen; $\mathrm{KCl}$ : Potassium chloride; MgCl2: Magnesium chloride; dNTP: pmol/ $\mu \mathrm{L}$, picomoles per microliter; FCS: Fetal calf serum; MI: Morphology index; NGY: Cells/ml. cells per microliter; HEPES: PMN/mL, polymorphonuclear per microliter; bp: Base pairs; Pz: Phospholipase zone.
\end{abstract}

\section{Competing interests}

The authors declare that they have no competing interests.

\section{Authors' contributions}

WP and GM analyzed data, performed research; wrote the paper. VL permormed research, TI and EP, collected samples. All authors read and approve the final manuscript.

\section{Authors' information}

GM, Professor of Clinical Microbiology, Dept. de Análises Clínicas e Toxicológicas, Universidade Federal do Rio Grande do Norte, Brazil and Leader of the Laboratório de Micologia Médica e Molecular.

\section{Acknowledgements}

We are very grateful to the Conselho Nacional de Desenvolvimento Científico e Tecnológico (CNPq) grant Edital Universal 14/2011 and to the Coordenação de Aperfeiçoamento de Pessoal de Nível Superior (CAPES) grant PROCAD CAPES NF-2008 for financial support. We also would like to thank Prof. Arnaldo Lopes Colombo for the donation of control strains and support with dendrogram analysis. 


\section{Author details}

${ }^{1}$ Laboratório de Micologia Médica e Molecular, Departamento de Análises Clínicas e Toxicológicas, Universidade Federal do Rio Grande do Norte, Natal, Rio Grande do Norte, Brazil. ²Departamento de Infectologia, Universidade Federal do Rio Grande do Norte, Natal, Rio Grande do Norte, Brazil. ${ }^{3}$ Departamento de Análises Clínicas, Universidade Estadual de Maringá, Maringá, Paraná, Brazil. 'Universidade Federal do Rio Grande do Norte, Centro de Ciências da Saúde, Departamento de Análises Clínicas e Toxicológicas, Laboratório de Micologia Médica e Molecular. Rua Gal. Gustavo Cordeiro de Faria S/N. Petrópolis, Natal, Rio Grande do Norte, Brazil.

Received: 14 September 2013 Accepted: 5 March 2014

Published: 15 March 2014

\section{References}

1. Lortholary O, Petrikkos G, Akova M, Arendrup MC, Arikan-Akdagli S, Bassetti M Bille J, Calandra T, Castagnola E, Cornely OA, Cuenca-Estrella M, Donnelly JP, Garbino J, Groll AH, Herbrecht R, Hope WW, Jensen HE, Kullberg BJ, Lass-Flörl C, Meersseman W, Richardson MD, Roilides E, Verweij PE, Viscoli C, Ullmann AJ, ESCMID Fungal Infection Study Group: ESCMID guideline for the diagnosis and management of Candida diseases 2012: patients with HIV infection or AIDS. Clin Microbiol and Infect 2012, 18:68-77.

2. Patel PK, Erlandsen JE, Kirkpatrick WR, Berg DK, Westbrook SD, Louden C, Cornell JE, Thompson GR, Vallor AC, Wickes BL, Wiederhold NP, Redding SW, Patterson TF: The changing epidemiology of oropharyngeal Candidiasis in patients with HIV/AIDS in the era of antiretroviral therapy. AIDS Res Treat 2012, 2012:262471.

3. Milan EP, Kallás EG, Costa PR, Da M, DA Colombo AL: Oral colonization by Candida spp. among AIDS household contacts. Mycoses 2001, 44:273-277.

4. Lalla RV, Latortue MC, Hong CH, Ariyawardana A, D'Amato-Palumbo S, Fischer DJ, Martof A, Nicolatou-Galitis O, Patton LL, Elting LS, Spijkervet FK, Brennan MT, Fungal Infections Section, Oral Care Study Group, Multinational Association of Supportive Care in Cancer (MASCC)/International Society of Oral Oncology (ISOO): A systematic review of oral fungal infections in patients receiving cancer therapy. Support Care Cancer 2010, 18:985-992.

5. Oliveira MA, Carvalho LP, Gomes MS, Bacellar O, Barros TF, Carvalho EM: Microbiological and immunological features of oral candidiasis. Microbiol Immunol 2007, 51:713-719.

6. Calderone RA: Candida and Candidiasis. ASM Press; 2011:544.

7. Mayer FL, Wilson D, Hube B: Candida albicans pathogenicity mechanisms. Virulence 2013, 9:119-128.

8. Sardi JC, Duque C, Höfling JF, Gonçalves RB: Genetic and phenotypic evaluation of Candida albicans strains isolated from subgingival biofilm of diabetic patients with chronic periodontitis. Med Mycol 2012, 50:467-475.

9. McManus BA, Maguire R, Cashin PJ, Claffey N, Flint S, Abdulrahim MH, Coleman DC: Enrichment of multilocus sequence typing clade 1 with oral Candida albicans isolates in patients with untreated periodontitis. J Clin Microbiol 2012, 50:3335-3344

10. Al-Mohaya MA, Azmi D, Al-Khudair W: Oral fungal colonization and oral candidiasis in renal transplant patients: the relationship to Miswak use. Oral Surg Oral Med Oral Pathol Oral Radiol Endod 2002, 93:455-460.

11. de la Rosa-García E, Mondragón-Padilla A, Irigoyen-Camacho ME, Bustamante-Ramírez MA: Oral lesions in a group of kidney transplant patients. Med Oral Patol Oral Cir Bucal 2005, 10:196-204.

12. Güleç AT, Demirbilek M, Seçkin D, Can F, Saray Y, Sarifakioglu E, Haberal M: Superficial fungal infections in 102 renal transplant recipients: a case-control study. J Am Acad Dermatol 2003, 49:187-192.

13. Chaves GM, Diniz MG, da Silva-Rocha WP, de Souza LB, Gondim LA, Ferreira MA: Species distribution and virulence factors of Candida spp. isolated from the oral cavity of kidney transplant recipients in Brazil. Mycopathologia 2013, 175:255-263.

14. Classification and diagnostic criteria for oral lesions in HIV infection: ECclearinghouse on oral problems related to HIV infection and WHO collaborating centre on oral manifestations of the immunodeficiency virus. J Oral Pathol Med 1993, 22:91-289.

15. Alves SH, Milan EP, de Laet Sant'Ana P, Oliveira LO, Santurio JM, Colombo $\mathrm{AL}$ : Hypertonic sabouraud broth as a simple and powerful test for Candida dubliniensis screening. Diagn Microbiol Infect Dis 2002, 43:85-86.

16. Casali AK, Goulart L, Rosa e Silva LK: Molecular typing of clinical and environmental Cryptococcus neoformans isolates in the Brazilian state Rio Grande do Sul. FEMS Yeast Res 2003, 3:405-415.
17. McCullough MJ, Clemons KV, Stevens DA: Molecular and phenotypic characterization of genotypic Candida albicans subgroups and comparison with Candida dubliniensis and Candida stellatoidea. J Clin Microbiol 1999, 37:417-421.

18. Merson-Davies LA, Odds FC: A morphology index for characterization of cell shape in Candida albicans. J Gen Microbiol 1989, 135:3143-3152.

19. Price MF, Wilkinson ID, Gentry LO: Plate method for detection of phospholipase activity in Candida albicans. Sabouraudia 1982, 20:7-14

20. Fradin CP, De Groot P, Maccallum D, Schaller M, Klis F, Odds FC, Hube B: Granulocytes govern the transcriptional response, morphology and proliferation of Candida albicans in human blood. Mol Microbiol 2005, 56:397-415

21. Chaves GM, Silva WP: Superoxide dismutases and glutaredoxins have a distinct role in the response of Candida albicans to oxidative stress generated by the chemical compounds menadione and diamide. Mem Inst Oswaldo Cruz 2012([online]):107.

22. Anees MM, Reich A, Hirschberg L, Watorek E, El-Shinnawi UM, Ibrahiem TM, El-Shaarawy S, Szepietowski JC: Enhanced enzymatic activit of Candida species responsible for oral candidiasis in renal transplant recipients. Mycoses 2011, 54:337-344.

23. Zahir RA, Himratul-Aznita WH: Distribution of Candida I the oral cavity and its differentiation based on the internall transcribed spacer (ITS) regions of rDNA. Yeast 2013, 30:13-23.

24. Takagi Y, Fukano H, Shimozato K, Tanaka R, Horii T, Kawamoto F, Kanbe T: Genotypes of Candida albicans isolated from healthy individuals and their distribution in patients with oral candidiasis. $J$ Infect Chemother 2013, [Epub ahead of print].

25. Odds FC, Jacobsen MD: Multilocus sequence typing of pathogenic Candida species. Eukaryot Cell 2008, 7:1075-1084.

26. Da Matta DA, Melo AS, Guimarães T, Frade JP, Lott TJ, Colombo AL: Multilocus sequence typing of sequential Candida albicans isolates from patients with persistent or recurrent fungemia. Med Mycol 2010, 48:757-762.

27. Odds FC, Davidson AD, Jacobsen MD, Tavanti A, Whyte JA, Kibbler CC, Ellis DH, Maiden MC, Shaw DJ, Gow NA: Candida albicans strain maintenance, replacement, and microvariation demonstrated by multilocus sequence typing. J Clin Microbiol 2006, 44:3647-3658.

28. Odds FC, Bougnoux ME, Shaw DJ, Bain JM, Davidson AD, Diogo D, Jacobsen MD, Lecomte M, Li SY, Tavanti A, Maiden MC, Gow NA, d'Enfert C: Molecular phylogenetics of Candida albicans. Eukaryot Cell 2007, 6:1041-1052.

29. Chaves GM, Santos FP, Colombo AL: The persistence of multifocal colonisation by a single $A B C$ genotype of Candida albicans may predict the transition from commensalism to infection. Mem Inst Oswaldo Cruz 2012, 07:198-204.

30. Jacobsen MD, Duncan AD, Bain J, Johnson EM, Naglik JR, Shaw DJ, Gow NA Odds FC: Mixed Candida albicans strain populations in colonized and infected mucosal tissues. FEMS Yeast Res 2008, 8:1334-1338.

31. Ferreira-Paim K, Andrade-Silva L, Mora DJ, Pedrosa AL, Rodrigues V, Silva-Vergara $\mathrm{ML}$ : Genotyping of Cryptococcus neoformans isolated from captive birds in Uberaba, Minas Gerais, Brazil. Mycoses 2011, 54:e294-e300.

32. Sampaio P, Gusmão L, Alves C, Pina-Vaz C, Amorim A, Pais C: Highly polymorphic microsatellite for identification of Candida albicans Strains. J Clin Microbiol 2003, 41:552-557.

33. Soll DR: The ins and outs of DNA fingerprinting the infectious fungi. Clin Microbiol Rev 2000, 13:332-370.

34. Dongari-Bagtzoglou A, Kashleva H, Dwivedi P, Diaz P, Vasilakos J: Characterization of mucosal Candida albicans biofilms. PLOS ONE 2009 4:e7967.

doi:10.1186/1472-6831-14-20

Cite this article as: da Silva-Rocha et al:: Candida species distribution, genotyping and virulence factors of Candida albicans isolated from the oral cavity of kidney transplant recipients of two geographic regions of Brazil. BMC Oral Health 2014 14:20. 